\title{
CASAS GÓMEZ, M. Y HUMMEL, M. (2017): SEMÁNTICA LÉXICA. VOLUMEN MONOGRÁFICO EXTRAORDINARIO DE RILCE. REVISTA DE FILOLOGÍA HISPÁNICA, 33.3, PAMPLONA: UNIVERSIDAD DE NAVARRA
}

\author{
Mercedes Ramírez SAlado \\ Instituto Universitario de Investigación en Lingüística Aplicada \\ Universidad de Cádiz \\ mercedes.ramirez@uca.es
}

Esta obra monográfica sobre semántica léxica, editada por Casas Gómez y Hummel, se inserta, como volumen extraordinario, en RILCE. Revista de Filología Hispánica, siendo, a su vez, fruto del encuentro de numerosos investigadores en la sección temática "Nuevos contenidos y perspectivas actuales de la semántica léxica” del XX Deutscher Hispanistentag, celebrado en la Universidad de Heidelberg en 2015. Este volumen colectivo se compone de dieciocho trabajos que, partiendo de las limitaciones y nuevos retos de la semántica léxica, aborda reflexiones teóricas y metodológicas sobre la materia y realiza un acercamiento a la teoría semántica en los estudios de casos para terminar tratando la semántica léxica y sus interfaces, con especial atención a cuestiones vinculadas a la neología y la terminología en el marco de esta disciplina.

Así, el primer objetivo que se plantean los editores del libro es la revisión de los planteamientos tradicionales de la lexicología, con el fin de determinar qué aspectos y contenidos siguen vigentes en la semántica léxica actual. Para ello, se sirven del cotejo de las distintas posturas metodológicas, contrastando enfoques tradicionales con los paradigmas más recientes, hasta lograr establecer qué nuevos contenidos se han incorporado a la semántica léxica y cuáles son las líneas de trabajo y perspectivas futuras.

De este modo, la sección introductoria "Limitaciones y nuevos retos de la semántica léxica" se inicia con un recorrido por la semántica léxica en su contexto internacional, donde los autores, Casas Gómez y Hummel, muestran la escasez de trabajos sobre semántica léxica que se producen en el ámbito hispánico, frente a la tradición histórica existente en países como Alemania o Francia. Esto nos lleva a pensar que, efectivamente, en numerosas ocasiones, los estudios sobre semántica en español están basados o, como afirman los propios autores, importados, de otros trabajos desarrollados en el panorama internacional

Para citar esta reseña / To cite this book review: Ramírez Salado, Mercedes (2019). Reseña de Casas Gómez, M., Hummel, M. Semántica léxica. Volumen monográfico extraordinario de Rilce. Revista de filología hispánica, 33.3, Pamplona: Universidad de Navarra, 2017. ELUA, 33: 257-263. doi: 10.14198/ELUA2019.33.14

Enlace / Link: http://dx.doi.org/10.14198/ELUA2019.33.14 
por autores como Pottier, Coseriu, Geckeler o Wotjak. Seguidamente, se plantean algunas de las limitaciones de la semántica léxica en su devenir como disciplina, como pueden ser las distinciones entre significado léxico y significado gramatical o la exclusión de la realidad extralingüística y la función referencial del marco de la semántica, restricciones estas que actualmente se desdibujan, pues se hace necesaria, en la semántica léxica, una interfaz semántico-gramático-pragmática que reconozca claramente la interrelación entre estos tipos de estudios. Precisamente, esta idea de los autores de tratar los puntos de encuentro entre semántica, sintaxis o pragmática muestra el camino que ha tomado la lingüística en los últimos tiempos, con un carácter eminentemente transversal que no se produce solo entre las disciplinas lingüísticas y no lingüísticas (como es el caso de la lingüística aplicada), sino también entre las propias ramas tradicionalmente lingüísticas.

No obstante, esta primera parte de la obra incluye un aspecto sumamente interesante para el desarrollo del resto de trabajos, puesto que aquí se detallan los nuevos contenidos y perspectivas de la semántica léxica, que podemos clasificar y resumir en: a) todos aquellos ámbitos de los que ya se ocupaba la lexicología clásica (cambio semántico, relaciones de significación, campos léxicos, el signo y sus componentes, etc.); b) la formación de palabras; c) las relaciones entre léxico y sintaxis; d) la variación semántica del léxico; e) la terminología y las unidades terminológicas; f) las locuciones; g) la neología y los neologismos, y h) la dimensión neurocognitiva del léxico.

Tras esta presentación inicial y siguiendo la línea argumental de toda la obra, hallamos una primera sección específica donde se muestran diversas reflexiones teóricas y metodológicas en el marco de la semántica léxica, en la que contribuyen los autores Rosario González Pérez, sobre las combinaciones léxicas sinestésicas; María Dolores Muñoz Núñez, sobre la conexión de la polisemia léxica con la interfaz léxico-sintaxis; Inmaculada Penadés Martínez, sobre el concepto de colocación; Miguel Rosso Carrasco, sobre la concepción de una semántica del hablar a partir del estructuralismo, y Carmen Varo Varo, sobre la neurosemántica.

Seguidamente, se dedica un bloque al papel de la teoría semántica en los denominados estudios de casos, donde realizan aportaciones Cristina Buenafuentes de la Mata, abordando la función de la semántica cognitiva en la formación de palabras por composición; Nicole Delbecque, tratando los fenómenos de cuantificación y aspecto en una determinada frase nominal; Gérard Fernández Smith, exponiendo aspectos pragmáticos y discursivos de los usos eufemísticos en la comunicación pública; Jairo Javier García Sánchez, afrontando un estudio semántico de un grupo de preverbios a partir de sus orígenes latinos; Ana Paz Afonso, aplicando la teoría de los prototipos al estudio diacrónico de los verbos de movimiento, y M $\mathrm{M}^{\mathrm{a}}$ Azucena Penas Ibáñez, detallando los procesos que tienen lugar al establecer las denominaciones de las categorías de color.

La tercera sección específica versa sobre las interfaces de la semántica léxica y en ella encontramos los trabajos de $\mathrm{M}^{\mathrm{a}}$ Tadea Díaz Hormigo, sobre la sintagmática suboracional del léxico derivado; Luis Escoriza Morera, sobre el papel de las marcas sociolingüísticas en la descripción semántica del léxico, y Ricardo Maldonado, sobre la conformación del sentido pragmático a partir de la estructura semántica y conceptual. El último grupo de contribuciones se centra en la terminología y la neología, siendo los autores María García Antuña, tratando las relaciones conceptuales en la terminología; Gloria Guerrero Ramos, describiendo las nuevas orientaciones de la terminología y la neología en el marco de la 
semántica léxica, y Érika Vega Moreno junto a Elisabet Llopart Saumell, delimitando los conceptos de novedad y neologicidad.

Como se puede observar, son temáticas bien diferenciadas, aunque unidas mediante un nexo común, lo que prueba que todas ellas se construyen bajo una misma base, en este caso, la semántica léxica y sus distintos contenidos, perspectivas e interfaces. Por esta razón, consideramos que, aunque la obra se ha estructurado en torno a cuatro ejes temáticos, los trabajos desarrollados pueden entenderse en más de una sección, pues todos se encuentran perfectamente insertos en la teoría semántica y plantean aspectos metodológicos y, en muchos casos, prácticos del ámbito de la semántica léxica. Así, a continuación, trataremos de mostrar en qué medida quedan cubiertos los nuevos contenidos y perspectivas de la actual semántica léxica en el volumen reseñado, partiendo de la clasificación de la semántica léxica establecida por Casas y Hummel en la introducción del mismo.

Resultaría esperable que, debido al carácter novedoso de los estudios que se plantean en los distintos trabajos que conforman esta obra, no se abordasen cuestiones relativas a los contenidos más tradicionales de la lexicología. Sin embargo, dado que los propios editores incluyen los viejos contenidos de la lexicología dentro de la actual semántica léxica, encontramos algunas contribuciones que giran en torno a esta temática, como pueden ser las de Rosso Carrasco, Paz Afonso y Penas Ibáñez, si bien no son los únicos que tratan de uno u otro modo aspectos de la lexicología tradicional, como las relaciones de significación, las oposiciones semánticas, los campos léxicos o los niveles del significar.

Centrándonos en los autores citados, observamos que el cuestionamiento de Rosso Carrasco sobre la consistencia o inconsistencia de una semántica del hablar desde presupuestos estructuralistas deriva en una comparación entre dos autores concretos, en este caso el lingüista rumano Eugenio Coseriu, como representante del funcionalismo, y el filósofo francés Paul Ricœur, como autor representativo de la tradición fenomenológico-hermenéutica. Asimismo, realiza una interesante contribución al insertar y explicar la semántica del hablar desde una perspectiva cognitivista. Finalmente, el autor llega a la conclusión de que, desde el estructuralismo, no se puede efectuar una descripción de la semántica del hablar que no presente algún tipo de contradicción, es decir, existe inconsistencia en una semántica del hablar desde los presupuestos estructuralistas.

Por otra parte, Paz Afonso muestra la teoría de los prototipos como una herramienta de gran utilidad para el estudio diacrónico del léxico, aunque centra su contribución en los verbos de movimiento en español, concretamente, en los verbos salir y exir. Para llevar a cabo su investigación, parte, fundamentalmente, de los conceptos semánticos de campo léxico, lexema, archilexema, sema, oposición y dimensión, a partir de los cuales avanza hasta la teoría de los prototipos, que nos permite acercarnos a la relación entre lengua y pensamiento. Consideramos especialmente interesante, en este sentido, la exposición que realiza la autora sobre los aspectos positivos y las carencias que presenta el cognitivismo a la hora de desarrollar un estudio como el que aquí se recoge.

En el caso del trabajo de Penas Ibáñez, lo situamos entre los estudios propios de la lexicología tradicional debido a sus contenidos relativos a la esencia del significado y a su vinculación con los campos léxicos. No obstante, debido a la reflexión que lleva a cabo la autora sobre las categorías del color y su conceptualización a partir de procesos ontogenéticos y semántico-cognitivos, podría incluirse también en algunas de las áreas más recientes de la semántica léxica. Así, partiendo desde el punto de vista de la física y, en cierto modo, 
de la biología, queda explicada la existencia de colores primarios, siendo estos el rojo, verde y azul, por ser percibidos con mayor sensibilidad por tres sectores del ojo situados en la parte central de la retina. En cambio, esto no se corresponde con lo que se categoriza en las lenguas, pues, desde el punto de vista semántico, no todas distinguen el mismo cromatismo, lo que la autora ejemplifica con lenguas como el pemán, yukpa, pirahã, chino antiguo, shona o bassa, entre otras. De acuerdo con Penas Ibáñez, los aspectos ontogenéticos relacionados con los términos básicos del color se trasladan a la lengua mediante procesos semánticos figurados y metonímicos que muestran un claro sentido connotativo, por lo que concluye que el relativismo lingüístico puede ser un mecanismo fundamental para explicar que, aunque tengamos la misma percepción del color, estructuramos las denominaciones y categorías del color según nuestra cultura.

Como hemos comentado previamente, estas tres contribuciones muestran cierta predominancia de contenidos tradicionales, pero esto no significa que no supongan nuevas aportaciones ni, por supuesto, que los trabajos que siguen no incluyan aspectos o planteamientos vinculados a las perspectivas de estudio de la vieja lexicología, sino más bien que encontramos en ellos el foco dirigido hacia la nueva visión de la semántica léxica. En este sentido, podemos situar, en relación a la formación de palabras, a Buenafuentes de la Mata y a García Sánchez. La primera se centra en la composición, ya que esta se ha entendido generalmente como un proceso de creación de voces que resultan semánticamente transparentes, pero esto no siempre es así. De este modo, Buenafuentes plantea la semántica cognitiva como un modelo idóneo para la explicación de aquellos casos que no presentan la claridad semántica propia de los compuestos, recurriendo a numerosos ejemplos en los que en el compuesto intervienen la metáfora y/o la metonimia. Finalmente, la autora entiende que la semántica léxica actual supera el alcance de la lexicología tradicional, pues no se ocupa solo de los mecanismos de creación léxica, sino también de la creación de nuevos significados entre otras cuestiones semánticas.

Por su parte, García Sánchez lleva a cabo un estudio diacrónico de los prefijos verbales ante-, pre-, pos $(t)$ - y sub- para explicar la modificación semántica que estos provocan en el español a partir de su origen en el latín. Así, el autor parte de un análisis diacrónico con claras referencias a la situación actual del español, es decir, incluyendo valoraciones de carácter sincrónico, al mismo tiempo que analiza si las modificaciones del contenido son heredadas del latín (modificación lexemática recibida) o si se han producido innovaciones (modificación lexemática innovada). En este trabajo se puede apreciar una clara convergencia entre la semántica morfológica y la semántica léxica, pues, como venimos observando, la formación de palabras se encuentra en la intersección entre morfología y semántica léxica.

Uno de los ámbitos de la semántica léxica que mayor presencia tiene en el volumen reseñado es el de las relaciones entre léxico y sintaxis, ya que, bajo esta perspectiva, podemos recoger los trabajos de González Pérez, Muñoz Núñez, Delbecque, Díaz Hormigo y Maldonado, si bien reiteramos que en modo alguno debe considerarse que estos autores no tratan aspectos relativos a otros ámbitos de la semántica léxica actual en sus respectivas investigaciones, pues precisamente el constante trasvase de contenidos entre los distintos ámbitos es uno de los fundamentos de la obra editada por Casas y Hummel.

González Pérez parte del tradicional interés de la lexicología por el estudio de determinadas relaciones léxicas desarrolladas en la dimensión paradigmática para adentrarse, desde la semántica léxica moderna, en el estudio de aquellas relaciones que tienen lugar en la di- 
mensión sintagmática. Para esta tarea, la autora plantea la sinestesia como una herramienta de gran utilidad para el análisis de la relación entre estructuras paradigmáticas y sintagmáticas. Así pues, entiende la sinestesia en lingüística como la combinación de lexemas en el sintagma a partir de una transferencia entre distintos dominios de percepción sensorial, lo que da lugar a asociaciones sintagmáticas que generan sentidos nuevos, por tanto, la autora muestra que la sinestesia nos permite hacer comunicable el pensamiento a través de una determinada formalización lingüística.

En el caso del trabajo realizado por Muñoz Núñez, hallamos la polisemia como eje central y, de un modo más específico, afronta la distinción entre las variantes e invariantes de contenido, conceptos que la autora llega a plantearse como meros constructos del lingüista que no tienen cabida en la realidad de los hablantes, puesto que no es posible abarcarlos desde la diastratía, la diafasía o la diatopía. Ya adentrándonos en la proyección del léxico en la sintaxis, Muñoz Núñez se centra en las locuciones, con especial atención a verbos de estado y logro, de los que se suele afirmar que no permiten cuantificadores de grado ni construcciones progresivas, pero que la autora prueba con numerosos ejemplos que son muchas las ocasiones en que sí es posible la presencia de estos elementos que expanden el dominio mental o desencadenan interpretaciones iterativas.

Por su parte, Delbecque desarrolla un minucioso análisis de la frase nominal [un caudal de $N]$ teniendo en cuenta el potencial cuantificador de dicha estructura. Observamos un enfoque cognitivo y conceptual en esta investigación que llega a determinar que los fenómenos hídricos implican fenómenos naturales de carácter dinámico que presentan en las construcciones lingüísticas dimensiones cuantitativas-espaciales y aspectuales. A través de un estudio de corpus, la autora establece una gradación en la expansión sintagmática de la frase nominal citada, variando dicha gradación en función de factores semánticos y discursivos.

Díaz Hormigo centra su aportación en la sintagmática suboracional del léxico derivado, por lo que ya desde el propio título podemos deducir la interfaz entre la morfología, la semántica léxica y la sintaxis, lo que se mantiene presente a lo largo de todo el texto. Precisamente en esta contribución, situada en una clara intersección entre varias áreas lingüísticas, se muestra que los límites entre la semántica morfológica y la semántica léxica no son en absoluto tajantes y que el trasvase de contenidos es constante, al mismo tiempo que plantea los aspectos semánticos como punto de unión entre la morfología y la sintaxis. Asimismo, la autora delimita las disciplinas lingüísticas que se encargan del estudio del contenido y, para ello, se sirve de la demarcación de Ullmann y las distinciones establecidas entre lo lexicológico y lo gramatical o morfológico de Coseriu. Finalmente, a través del estudio del léxico derivado, la autora hace patente la interrelación entre varias subdisciplinas semánticas (semántica morfológica, semántica léxica, semántica suboracional y semántica oracional).

Respecto al trabajo de Maldonado, debemos destacar que se sitúa en una interfaz entre sintaxis, semántica y pragmática, mostrando estas áreas como un continuo interconectado que lo llevan a abordar la conformación del sentido a partir del análisis de las estructuras semántica y conceptual. Para ello, se sirve de un estudio del marcador discursivo claro y otro sobre el conector según, a través del cual concluye que el análisis semántico se presenta como un elemento esencial para la comprensión del sentido pragmático, pues lo semántico conforma en última instancia el contenido pragmático.

De la variación semántica del léxico se ocupan, principalmente, Fernández Smith y Escoriza Morera. El primero afronta el estudio del fenómeno eufemístico en el discurso 
público, situando aspectos pragmáticos y discursivos dentro del marco de la semántica léxica y planteando el eufemismo como una estrategia de atenuación en el discurso público, porque, gracias a los usos eufemísticos, el emisor puede desactivar contextos que no le son favorables en el intercambio comunicativo. Para este autor, la semántica léxica juega un papel fundamental en materias como la pragmática, el análisis del discurso, la retórica o la estilística, debido, sobre todo, a la relevancia de las unidades léxicas y sus posibles variantes en el proceso de interpretación del sentido de un texto. En cuanto al trabajo de Escoriza Morera, hallamos claras referencias al fenómeno de la variación, ya que muestra la sociolingüística variacionista como un mecanismo para el análisis contextual del léxico. De hecho, el análisis de factores sociocontextuales nos parece, al igual que al autor, de gran utilidad para la descripción del uso de unidades léxicas, porque nos permitirían comprobar el uso real que hacen los hablantes de aquellas unidades léxicas que se consideran variantes de expresión. De este modo, Escoriza Morera plantea la sociolingüística, o más bien las técnicas metodológicas de la sociolingüística, como un modo de hacer investigación práctica sobre el tratamiento del léxico a partir de estudios semánticos.

La terminología y las unidades terminológicas es otro de los ámbitos de los que hoy en día se ocupa la semántica léxica y, en consecuencia, este volumen recoge diversas referencias a estos conceptos. Específicamente, los trabajos de García Antuña y Guerrero Ramos prestan especial atención a estas cuestiones, pues García Antuña centra su contribución en las relaciones conceptuales en terminología, realizando un recorrido por varias tipologías, como las desarrolladas por Wüster, Arntz y Picht, Cabré o Casas Gómez. A partir de esta última, ejemplifica ampliamente los distintos tipos de relaciones conceptuales empleando unidades terminológicas propias del léxico de la marroquinería. Finalmente, sitúa las relaciones lógico-designativas características del ámbito terminológico dentro de las relaciones en semántica y elabora una propuesta propia sobre los tipos de relaciones conceptuales en terminología. Por su parte, Guerrero Ramos afronta las nuevas orientaciones de la terminología y la neología en el marco de la semántica léxica, por lo que su contribución puede situarse tanto en el campo de la terminología como en el de la neología. No obstante, antes de adentrarse en las nuevas orientaciones, la autora realiza un recorrido histórico por ambas materias para llevar a cabo una revisión de la situación actual tanto de la terminología como de la neología. Resulta destacable que las dos materias abordadas en este trabajo tienen su punto de encuentro cuando Guerrero Ramos trata la neología especializada (neonimia), aportando datos, sobre todo, desde la Teoría Comunicativa de la Terminología, que muestran las implicaciones pragmático-discursivas que conllevan los neologismos terminológicos.

Si bien el trabajo de Penadés Martínez podría situarse en el marco de las relaciones entre léxico y sintaxis, optamos por enmarcarlo en el estudio de las locuciones, ya que sitúa el foco de la investigación en torno al concepto de colocación, pero lo hace mediante un tipo concreto de colocación, en este caso la formada por un verbo más una locución adverbial. Para esta autora, solo se conforma una colocación cuando se combinan al menos dos unidades léxicas constituyendo una estructura sintáctica y busca comprobar, a partir de la estructura [verbo + locución adverbial], si el significado léxico influye de algún modo en la combinatoria sintáctica. Finalmente, tras examinar una serie de locuciones adverbiales, logra determinar que las colocaciones son estructuras sintagmáticas radiales, sistemáticas y semánticamente deducibles, por lo que pueden ser estudiadas dentro de la semántica léxica (relaciones semánticas sintáctico-pragmáticas). 
Tanto el ya citado trabajo de Guerrero Ramos, como el estudio elaborado por Vega Moreno y Llopart Saumell se ubican en la línea de la neología y en el vacío teórico que la rodea. En este sentido, podemos encontrar en la aportación de Guerrero Ramos una introducción sumamente clara y abarcadora de lo que supone la disciplina neológica, mientras que Vega Moreno y Llopart Saumell se centran en los conceptos, por un lado, de "neología" y "neologismo" y, por otro, de "neologicidad" y "novedad". Justamente, en torno a estos últimos, realizan una detallada revisión crítica de diversas propuestas de criterios de neologicidad, llevadas a cabo por autores tan representativos como Rey, Cabré, Fernández Sevilla, Estornell Pons o Méndez Santos. Así, siguiendo el hilo argumental de toda la obra, se tratan también aspectos morfológicos, semánticos y pragmáticos de los neologismos, todo ello complementado por ejemplos extraídos de las propias tesis doctorales de las autoras. El fin último del aporte de Vega y Llopart ha sido la elaboración de una reflexión y primera aproximación al concepto de neologicidad y los criterios en torno a este, incluyendo, además, nuevos enfoques.

Finalmente, también se circunscribe la dimensión neurocognitiva del léxico al marco de la actual semántica léxica, por lo que encontramos el trabajo de Varo Varo atendiendo a este aspecto. En esta contribución predomina el reciente campo de la neurosemántica, surgido, fundamentalmente, a partir de los estudios sobre el procesamiento semántico. De esta forma, la autora analiza producciones de individuos afectados por déficits semánticos, concretamente, afasia anómica y demencia semántica, mediante los cuales prueba que la interpretación del significado léxico se puede concebir como una agrupación de rasgos semánticos que funcionan de manera asociativa, mientras que la información conceptual de las palabras se muestra sujeta a una serie de principios organizadores.

En definitiva, con esta obra se pone de manifiesto la relevancia del término transversalidad en el ámbito de la lingüística, en general, y de la semántica léxica, en particular, porque no solo se han incorporado nuevas vías de estudio, sino que se demuestra cómo la semántica léxica transfiere y recibe conocimientos de otras áreas tradicionalmente separadas de la semántica, como pueden ser la sintaxis, la pragmática, el análisis del discurso, la sociolingüística, la neurolingüística o la psicolingüística. Por todo ello, consideramos que se trata de un volumen monográfico sumamente necesario para la actualización de la semántica léxica actual, el cual permitirá devolver esta materia a la luz de las investigaciones más recientes, sirviendo de soporte teórico para el desarrollo de nuevos estudios. 